\title{
Isolation and Identification of Salmonella from Apparently Healthy Pet Dogs in Holeta Town, Western Shoa, Ethiopia
}

\author{
Sultan Aliyi ${ }^{1}$,Eyob Hirpa ${ }^{1 *}$, Olifan Zewude ${ }^{1}$ and Yohannes Equar ${ }^{2}$ \\ ${ }^{1}$ Wollega University, School of Veterinary Medicine, Ethiopia \\ ${ }^{2}$ Holeta Research Center and National Biotechnology Research Laboratory, Ethiopia
}

Submission: May 18, 2018; Published: June 07, 2018

*Corresponding author: Eyob Hirpa, Wollegw University, School of Veterinary Medicine, PO box 395, Ethiopia, Tel: +251933686525;

Email: eyobresearch@gmail.com

\begin{abstract}
Salmonellosis is one of the most important Zoonotic diseases with global distribution and importance in both humans and animals therefore, a cross-sectional study was carried out aimed at isolation and identification of Salmonella from rectal swab sample of apparently health dogs in Western Shoa, Holeta Town, from November, 2015 to February, 2016. Rectal Swab samples were collected from 123 selected apparently healthy pet dogs' by cluster sampling Technique for isolation and identification of Salmonella using standard operating procedure of ISO 6579, 2002. The overall detection rate of Salmonella were 17.1\% ( $\mathrm{n}=21)$. Moreover, $14.3 \%(\mathrm{n}=10)$ and 20.8\% $(\mathrm{n}=11)$ dogs were Salmonella positive in Burka Harbu and Goro Keransa, respectively. The higher detection rate of Salmonella were recorded in male $17.5 \%(\mathrm{n}=18)$ than female $15 \%(\mathrm{n}=3)$ however, the variation between sex were not statistically significant $(P>0.05)$. This study also revealed the highest rate in dogs those fed on all what is available including scavenging by $19.1 \%$ (9/47) while animal fed on home left over feed was second ranked 16.9\%,(10/59), but those fed only meat was $11.8 \%(2 / 17)$ and this variation also not statistically significant $(P>0.05)$. In conclusion, this study indicates that the detection rate in apparently healthy pet dog shedding of Salmonella from the Western Shoa Holeta Town is high relative to the other species of animal in the country and this show dog play the major role in spreading of the disease to the humans as well as other animals.
\end{abstract}

Keywords: Apparently healthy dogs; Holeta; Identification; Isolation; Salmonella

\section{Introduction}

Salmonellosis is one of the most important Zoonotic diseases with global distribution and importance in both humans and animals [1]. A number of animal species including ruminants, carnivores, birds and reptiles can play a major role as a carrier in the spread of Salmonellae and transmit them to other healthy animals and humans [2]. It can spread to humans by: close contact with infected animals including livestock, pets, exhibited animals or wildlife, contact with blood, urine or faeces of an infected animal, water or soil that has been contaminated by infected animals, eating or drinking unpasteurized dairy products, undercooked meat or unwashed fruit and vegetables that are contaminated with faeces from an infected animal [3] (Figure 1).

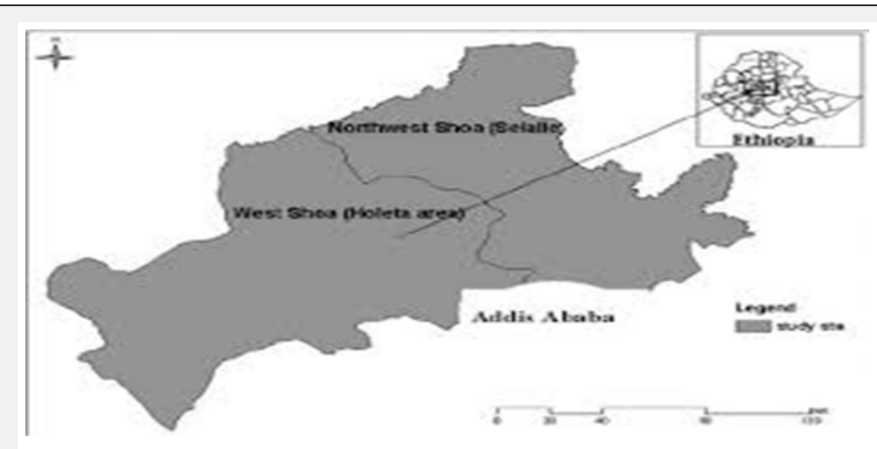

Figure 1: Map of study area West Shoa, Holeta town. 
Even if there is an infectious agent present, it does not always result in disease but, depend on three: factors; the infectious agent, a susceptible host and a way of spread [4]. People most at risk of being affected by a disease are those in close contact with animals or animal products including: veterinarians, farmers, abattoir workers, shearers, and people assisting with animal births, pet owners, pig hunters, children, elderly people, pregnant women and people with impaired immunity [5].

Today, dogs primarily live indoors, share living spaces with their owners, and assume integral roles as companion's family members or service animals. Companion animals are also increasingly used in therapeutic settings, for instance in psychotherapy, or to support AIDS patients, children with disabilities, orthopedic and cardiac patients, Alzheimer patients, or the elderly. The potential risks associated with such contacts, particularly for young children or immune-compromised patients, are difficult to quantify [6].

Recently, it is believed that the incidence of this disease is increasing in both man and animals. The intestinal carriage of Salmonella by dogs is very important to public health. Over the past 40 years, there have been several reports on transmission of Salmonella from dogs to humans [3]. The intimate relationship between dogs and their owners has the potential to increase the risk of human exposure to bacterial pathogens. In most dogs the infection occurs in latent form and they shed Salmonella in their feces and saliva for prolonged time (Figure 2) \& [7].

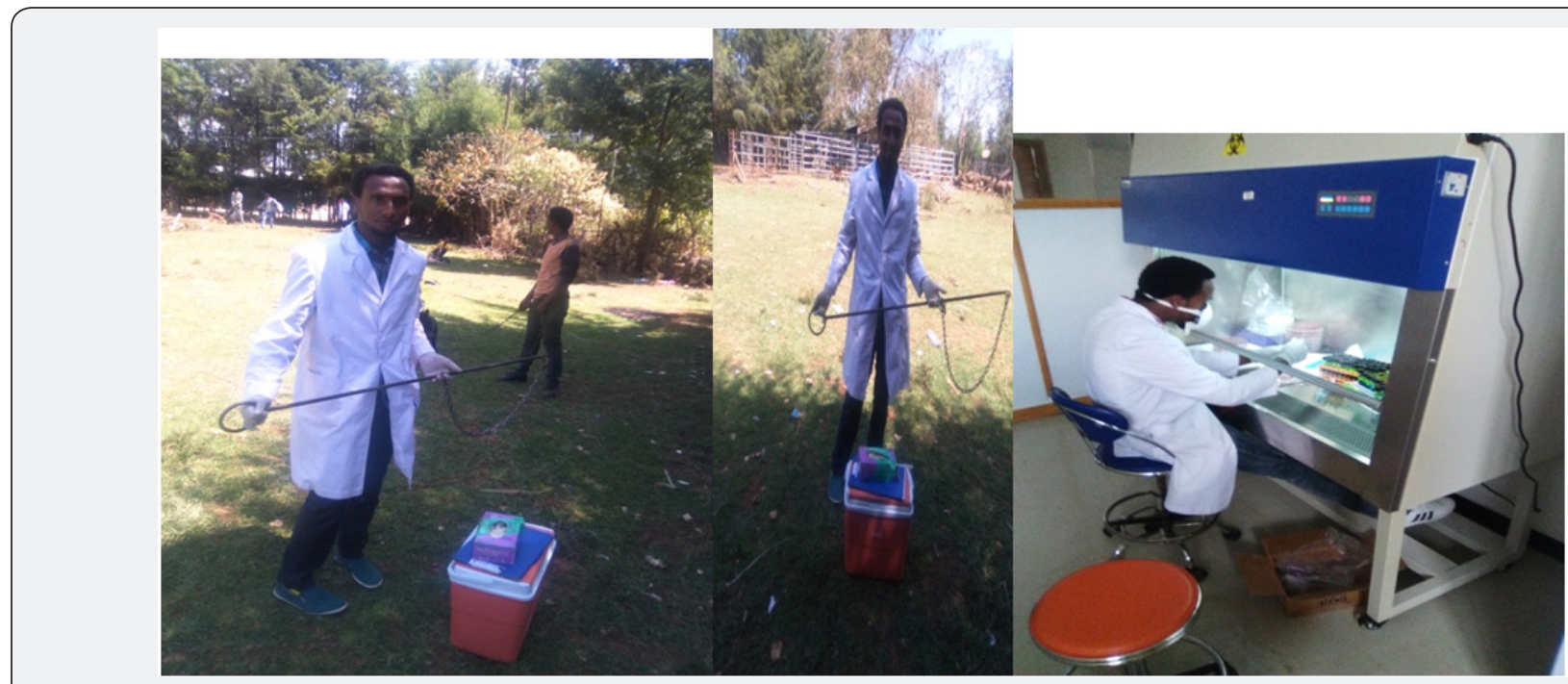

Figure 2: Picture shows sample collection and transportation to laboratory.

Most dogs are asymptomatic when they act as reservoirs of shedding Salmonellae in their feces [7]. Salmonella serovars readily colonize in the canine large intestine and mesenteric lymph nodes. Fecal shedding of the pathogen in naturally occurring infections probably continues for a period of at least 6 weeks. Since the lymph nodes harbor the agent, the carrier state may persist for much longer periods. Among different species, dogs can be one of the most important reservoirs of Salmonella for the following reasons: dogs are one of the most popular pets in close contact with their owners, including children, and they can shed the organism for weeks without any clinical signs [1].

Moreover, a high prevalence of infection caused by numerous serotypes has been confirmed in cats and dogs. These animals may be asymptomatic carriers or may suffer from gastroenteritis, Salmonellosis with varying degrees of severity. Dogs can contract the infection by eating the feces of other dogs, other domestic or per domestic animals or man. It can also be infected by ingestion of contaminated food and transmit the disease to man [8]. In
Ethiopia, there is paucity of information on the role of dogs as a potential source of Salmonella infection to humans despite an increased dog keeping in the country.

Therefore, the objective of this thesis is:

A. For isolation and identification of Salmonella in dogs and investigating the potential role of carrier status in pets' dog.

\section{Materials and Methodology}

\section{Study area}

The study was conducted in central Ethiopia, Holeta which located at $40 \mathrm{~km}$ west of Addis Ababa and at an elevation of 2400 m.a.s.l in the central Ethiopia (903' $\mathrm{N}$ and 38030'E). The area is characterized by mild subtropical weather, with average minimum and maximum annual temperatures of $6.3{ }^{\circ} \mathrm{C}$ and 22.1 ${ }^{\circ} \mathrm{C}$, respectively. Total population of city estimated to 25,593 both sex (male=12, 6058 and female=12,988). Moreover, experience bimodal rain fall pattern with a long rainy season extending 


\section{Current Trends in Biomedical Engineering \& Biosciences}

from July to September while the short rainy season extends from March to April [9].

\section{Target populations}

The target populations for this study were pet dogs in Holeta town. All samples were taken from apparently healthy dogs.

\section{Study design}

A cross- sectional study design was conducted from November, 2015 to February, 2016 for isolation and identification of Salmonella in rectal swab sample of pet dogs in Holeta towns, Oromia special zone surrounding Finfine (Figure 3).
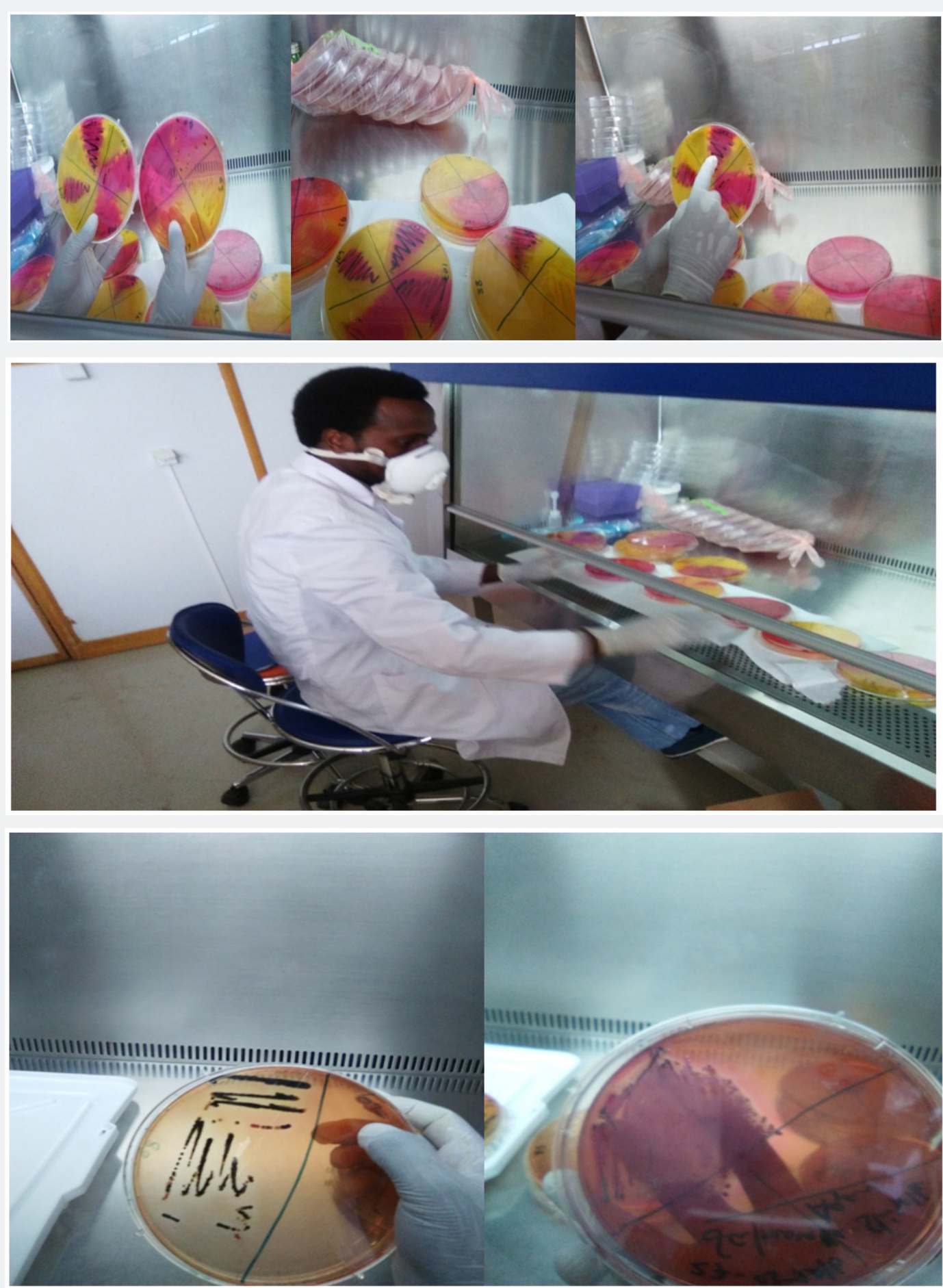

Figure 3: Pictures showing part of the activities in National animal biotechnology research laboratory and field sample collection. 


\section{Sample size determination and samling technique}

The study area was selected purposively and sample was taken from two randomly selected Kebeles out of four Kebeles in town, by using clusters sampling technique. All Apparently Healthy pet dogs in selected Kebele were sampled (i.e. from Goro Keransa $(n=53)$ and Burka Harbu $(n=70)$ Keble). A total of 123 rectal swab samples were collected from two Kebles, while information of age, sex, feeding system, origin and breeds of sampled animals were filled for each by interviewing their owners.

\section{Sample collection and transportation}

Rectal swab sample was obtained with sterile cottontipped applicators after restraining the animals. Commercially available cotton swabs were moistened in sterile saline solution before being inserted in the rectum and put on sterile plastic fecal collection cups which contain $5 \mathrm{ml}$ of sterile saline solution and transported ice-cooled to Animal Biotechnology Research Laboratory of National Agricultural Biotechnology Research Center at Holeta within 5 hours of collection for processing. Questionnaires were specifically prepared for each source of samples studied and information on age, breed, sex, feeding style and origin of animals sampled was obtained.

\section{Isolation and identification of Salmonella}

The isolation of Salmonella from rectal was performed after selective enrichment in $10 \mathrm{ml}$ of Rappaport-VassiliadisSoy peptone broth(RV; Oxoid, UK) and incubated at $37{ }^{\circ} \mathrm{C}$ for 24h(hour). A loopful of enriched broth was streaked on MacConkey Agar (Oxoid), Brilliant Green Agar (Oxoid Limited, Detroit, Mich., USA), Salmonella-Shigella (SS Agar) Agar,
Desoxycholate Citrate Agar and Xylose-Lysine Desoxycholate (XLD) (Oxoid) Agar plates and incubated at $37{ }^{\circ} \mathrm{C}$ for $24 \mathrm{~h}$. The plates were examined for the presence of typical colonies of Salmonella, i.e. pink colonies with or without black centers on XLD agar and colorless colonies on MacConkey agar, pink colonies on BGA and colorless colonies on SS agar were subjected to biochemical tests using standard methods. All presumptive Salmonella colonies were sub cultured onto Nutrient agar, at 37 ${ }^{\circ} \mathrm{C}$ for $24 \mathrm{~h}$, and further confirmed by convectional biochemical tests such as: Triple Sugar Iron (TSI) agar, Simmons Citrate agar, Methyl Red (MR) and Indole test to confirm at genera levels, as recommended by the guidelines of (ISO 6579, 2002) [10].

\section{Data analysis}

All data were entered into a Microsoft Excel spreadsheet and transferred to SPSS statistical package version 20 statistical software for analysis. Rate of detection of Salmonella by origin of sampled animal and associate risk factors were expressed as percentages. The prevalence was defined as the number of Salmonella positives per the number of samples examined. Pearson's chi-square test was used to compare the association of prevalence of Salmonella between selected Kebele and computation of descriptive statistics such as, frequency and percentage were applied to compute the questionnaires data.

\section{Results}

From a total of 123 dogs examined, 21 (17.1\%) were positive for Salmonellae-carrying. Of the dogs, from which Salmonellae were isolated, 70 (56.9\%) were from Goro Keransa and 53 (43.1\%) were from Burka Harbu Kebele. Moreover, 10 (14.3\%) and $10(20.8 \%)$ Salmonella positive dogs were encountered in Burka Harbu and Goro Keransa, respectively (Table 1).

Table 1: Selected Kebele, number of rectal swab sample; Salmonella positive number and percentages of dogs in study area.

\begin{tabular}{|c|c|c|c|}
\hline Kebele & Number & Number of Salmonella Positive & 10 \\
\hline Burka Harbu & 70 & 11 & 14.3 \\
\hline Goro Keransa & 53 & 21 & 20.8 \\
\hline Total & 123 & 17.1 \\
\hline
\end{tabular}

On the other hand, 17 (18.3\%) of infected dogs were less than or equal to two years, while $3(12.5 \%)$ of them were between two and six years age, but only $1(16.7 \%)$ animal detected in the age grouped old or above six years. It also indicate that, 18 (17.5\%) and $3(15 \%)$ positive animal were male and female, respectively. In line with this 17 (17.8\%) local and 4 (14.3\%) cross breed dogs were approved for Salmonella carrying. This study also revealed the highest rate of infection in dog fed on all what is available including scavenging by 9 (19.1\%) out of 47 dogs, while animal fed on home left over feed was second ranked 10 (16.9\%) out of 59 dogs, but those fed on meat was only two animals i.e., 2 $(11.8 \%)$ from 17 animals fed on meat during sample collection (Table 2).

Table 2: Age group, sex; breed and feed of dogs included in the study and number positive for Salmonella.

\begin{tabular}{|c|c|c|c|c|c|c|}
\hline Variable & Division Month/years & Frequency & Percentage (\%) & $\begin{array}{c}\text { Salmonella } \\
\text { Positive Number }\end{array}$ & $\begin{array}{l}\text { Pearson's Chi- } \\
\text { Square Value }\left(X^{2}\right)\end{array}$ & P Value \\
\hline \multirow{3}{*}{ Age } & Infant ( 0 up to 2 years) & 93 & 75.6 & $17(18.3 \%)$ & \multirow{3}{*}{0.451} & \multirow{3}{*}{0.798} \\
\hline & Adult (up to 6 years) & 24 & 19.5 & $3(12.5 \%)$ & & \\
\hline & Old (above 7 years) & 6 & 4.9 & $1(16.7 \%)$ & & \\
\hline
\end{tabular}




\section{Current Trends in Biomedical Engineering \& Biosciences}

\begin{tabular}{|c|c|c|c|c|c|c|}
\hline \multirow{3}{*}{ Sex } & Male & 103 & 83.7 & $18(17.5 \%)$ & 0.073 & 0.788 \\
\cline { 2 - 7 } & Female & 20 & 16.3 & $3(15 \%)$ & & 0.199 \\
\hline \multirow{3}{*}{ Breed } & Local & 95 & 77.2 & $17(17.9 \%)$ & 0.656 \\
\hline \multirow{3}{*}{ Feed } & Cross & 28 & 22.8 & $4(14.3 \%)$ & \\
\cline { 2 - 7 } & Meat & 17 & 13.8 & $2(11.8 \%)$ & 0.482 & 0.786 \\
\cline { 2 - 7 } & Home leftover & 49 & 48 & $10(16.9 \%)$ & & \\
\hline
\end{tabular}

\section{Discussion}

Apparently healthy dogs can harbor Salmonella and might thereby serve as a potential source of human infection with implications for public health. This study showed that the asymptomatically shading rate of Salmonella in pet dogs located in Holeta town of Central Ethiopia is $17.1 \%$ and first of its kind in the country. However, today's animal medicine estimated the prevalence of subclinical carriage of Salmonella in clinically healthy dogs to range from 0 to $44 \%[11,12]$ and the results of the current study are in agree with it. The prevalence of subclinical shedding of Salmonella in apparently healthy household dogs has been reported for a number of different countries, but it varies. A study of 150 dogs from Hawke's Bay, New Zealand showed an absence of subclinical carriage [13] which contradicts our finding. By contrast, a study of 251 dogs visiting parks in three cities in south-western Ontario, Canada reported Salmonella in $1.2 \%$ of the dogs [14], which is lower than the current finding.

This considerable geographical variation in the prevalence of Salmonella serotypes reported in dogs could be due to the sample size, year of sampling, sampling strategies, and isolation methods performed, but may also be due to cultural differences in feeding or hygiene practices or favorable climate conditions for bacterial growth and survival. The prevalence of Salmonella in dogs as reported in the literature is also highly variable depending on the immediate environment in which the animals live. For example, Salmonella isolation rates from stray dogs have been reported to be significantly higher than those from household dogs [15]. Rectal swabs from kennel dogs in Tehran, Iran indicated that 28 out of $181(15.5 \%)$ were positive for Salmonella [16], which is in line with our finding. In a shelter in Bursa, Turkey $11 \%$ of dogs tested positive for Salmonella [2], and in Japan, $5.9 \%$ of stray or unwanted apparently healthy dogs were positive for the presence of Salmonella in their intestinal contents [17], the two finding are agree with our finding. In northern Taiwan rectal swabs collected from 491 stray dogs in a municipal animal shelter found 6.3\% (31 dogs) dogs were positive for Salmonellae [15].

However, other studies involving strays or kenneled dogs show much lower rates of carriage that are not in line with the findings presented here [18] failed to detect Salmonellae in the intestinal contents of stray dogs $(n=100)$ in Trinidad, West Indies, and an analysis of rectal swabs collected from kenneled dogs in
Istanbul, Turkey found only one out of $100(1 \%)$ to be positive for Salmonella [19], which are far from our current report. Shedding of Salmonella in feces is also known to be common among the racing greyhound population. Racing greyhounds in the USA have been shown to have high rates of subclinical shedding of Salmonella at $44 \%$ [20], and a more recent study reported Salmonella in feces from $11 \%$ of asymptomatic greyhounds [21]. The high prevalence of Salmonella that are typically reported in greyhounds may be traceable to the high-protein raw meat diet provided for racing. A high prevalence of Salmonella in these raw meat diets has been reported and identical enterotypes have been found in the feces of dogs consuming the food, confirming that the diet is the likely source of Salmonella [22].

In some instances, the dogs may not be colonized by Salmonella and may just be passive carriers in which foodborne Salmonella is transiently passing through the intestines. However, studies have shown that raw meat diets contaminated with Salmonella can lead to abortions and high levels of morbidity and mortality in greyhounds through Salmonella infection $[23,24]$. In line to this, two dogs which fed on meat tested positive for Salmonella in current finding. In this study, the overall incidence of Salmonella detected in dogs was $17.1 \%$. The rate of Salmonella isolation is higher than that reported in Thailand (12.4\%) [25], but one study in USA (20.8\%) [26]. Reported more than our finding. Recently, one study reports very low prevalence of dog Salmonellosis in midland region of United Kingdom only one dogs $(0.23 \%)$ out of 436 dogs [27], which is far lower from current finding. This may be due to difference in study area, level of animal and public health and time of study. In Ethiopia, a prevalence of $5.3 \%$ to $15.4 \%$ was reported from investigation on rural and urban community by [28]

Current study agrees with upper scale, even though species variety is there. On the other hand, out of 300 meats sample examined in Addis Ababa by [29],14.7\% were Salmonella positive, which support our finding. However, one study in southern Ethiopia was carried out on 107 food handler, report only one person (0.93\%) being Salmonella carrier [30], which far from our finding. The cross-sectional nature of this investigation meant that only a single rectal swab sample was analyzed from each dog, which may be the reason that the prevalence of Salmonella was low. However, although the prevalence of Salmonella might have been higher if more than one rectal swab culture was performed on each dog. The limitations of single rectal swab cultures for the 
isolation of Salmonella, due to intermittent shedding, are well documented. Dogs with experimentally-induced latent infection shed the agent irregularly for the subsequent 3-4 weeks. In rare cases this shedding continues for up to 100 days [31,32]. Since the agent is being shed at intervals, sampling times are very important when searching the carrier status of the dogs and in the present study we can only conclude that the dogs were positive or negative for the presence of Salmonella at the time of sampling [33-35].

\section{Conclusion and Recommendations}

In conclusion, this study indicates that the detection rate in apparently healthy pet dog shedding of Salmonella from the Western Shoa Holeta Town is high relative to the other species of animal in the country and this show dogs might play the a role in spreading of the disease to the human as well as other animalsm [35-41].

Based up on the above conclusions the following recommendations are forwarded:

i. Anyone handling a pet or feces from a pet should wash their hands immediately afterwards with soap and running water or use an alcohol-based hand sanitizer.

ii. Dog feces should be picked up immediately to prevent environmental contamination, especially in public areas like parks where other dogs and children may play.

iii. Prevent pets from drinking from puddles, ponds, lakes or other water sources that may be contaminated with feces from other animals.

iv. Dogs should be strongly discouraged from eating their own feces or those of other animals.

v. Feeding a commercially prepared, heat-processed diet helps to reduce the risk of Salmonella contamination in the food, but even these products can occasionally contain Salmonella.

vi. Pet food should therefore be kept in a sealed container and should never come in contact with kitchen surfaces or food meant for human consumption.

vii. Do not leave wet pet food in dishes at room temperature for prolonged periods, as this provides ideal conditions for bacteria of many kinds to grow.

viii. Prevent pets from hunting and scavenging small wild animals and birds. .

ix. Regardless of these findings, the possibility that dogs may harbor Salmonella and other Zoonotic pathogens should not be ignored.

\section{References}

1. Zahraei T, Askari M, Madadgar O, Reza S, Ashrafi I (2013) Shepherd dogs as a common source for Salmonella Enterica serovars reading in garmsar Iran. Turkish Journal of Veterinary and Animal Sciences 37(1): 102-105

2. Kocabiyik AL, Cetin C, Dedicova D (2006) Detection of Salmonella spp. in Stray Dogs in Bursa Province Turkey: First Isolation of Salmonella Corvallis from Dogs. J Vet Med B Infect Dis Vet Public Health_ 53(4): 194-196.

3. The Center for Food Security and Public Health (CoFSPH) (2010) Emerging zoonotic diseases and your family, College of Veterinary Medicine, Iowa State University, USA.

4. Ibrahim A (2014) Bacterial load and isolation of Salmonella species from cattle carcasses at kano Abattoir- kano state, Ahmadu Bello University, Zaria, Nigeria.

5. Britton S (2015) Veterinary officer animal biosecurity orange, prime zoonoses: Animal diseases that may also affect people fact $814\left(2^{\text {nd }}\right.$ edn).

6. Hoelzer K, Moreno Switt AI, Wiedmann M (2011) Animal contact as a source of human non-typhoid salmonellosis. Vet Res 42: 34.

7. Abdelhakim KM, Arab RMH, Abouzeid AA, Samir A, Korany RMS (2014) Experimental salmonellosis in dogs. Clinical, Bacteriological and Pathological studies, Department of Infectious Diseases, Faculty of Veterinary Medicine, Cairo University, Giza, Egypt, Life science journal 11(10): 1176-1181.

8. PAHO (2001) Zoonoses and communicable diseases common to man and animals bacterioses and mycoses. Scientific and Technical Publication No 580, ( $3^{\text {rd }}$ edn), Washington, DC, USA 20037(1): 233246.

9. Population Census Commission (2007) The 2007 population and housing census of Ethiopia. Statistical Report for Oromia Region, Ethiopia.

10. ISO (International Organization for Standardization) 6579 (2002): Microbiology of food and animal feeding stuff- horizontal method for the detection of Salmonella spp. Geneva, Switzerland, pp: 511-525.

11. Carter ME, Quinn JP (2000) Salmonella infections in dogs and cats. CAB International, Wallingford, UK, pp. 231-244.

12. Sanchez S, Lee MD, Maurer JJ, Doyle MP, Hofacre CL (2002) Animal sources of salmonellosis in humans. J Am Vet Med Assoc 221(4): 492497.

13. Timbs DV, Davis GB, Carter ME, Carman MG (1975) The salmonella excretory incidence of dogs in Hawke's Bay. N Z Vet J 23: 54-56.

14. Procter TD, Pearl DL, Finley RL, Leonard EK, Janecko N, et al. (2014) A cross-sectional study examining campylobacter and other zoonotic enteric pathogens in dogs that frequent dog parks in three cities in south-western Ontario and risk factors for shedding of Campylobacter spp. Zoonoses Public Health 61(3): 208-218.

15. Tsai HJ, Huang HC, Lin CM, Lien YY, Chou CH (2007) Salmonellae and campylobacter in household and stray dogs in Northern Taiwan. Vet Res Commun 31: 931-939.

16. Shimi A, Keyhani M, Bolurchi M (1976) Salmonellosis in apparently healthy dogs. Vet Rec 98(6): 110-111.

17. Fukushima H, Nakamura R, Iitsuka S, Ito Y, Saito K (1985) Presence of Zoonotic pathogens (Yersinia species., Campylobacter jejuni, Salmonella spp., and Leptospira spp.) simultaneously in dogs and cats. Zentralbl Bakteriol Mikrobiol Hyg B 181(3-5): 430-440.

18. Ojo MO (1994) Pathogenic aerobic bacteria and fungi isolated from stray dogs in Trinidad. Rev Elev Med Vet Pays Trop 47(2): 179-181.

19. Baggigil AF, Ikiz S, Dokuzeylul B, Basaran B, Ozgur Y (2007) Fecal shedding of Salmonella spp. in dogs Bacteriology. J Vet Med Sci 69(7): 775-777. 
20. Stucker CL, Galton MM, Cowdery J, Hardy AV (1952) Salmonellosis in dogs. II. Prevalence and distribution in greyhounds in Florida. The Journal of Infectious Diseases 91(1): 6-11.

21. Stone GG, Chengappa MM, Oberst RD, Gabbert NH, McVey S, et al. (1993) Application of polymerase chain reaction for the correlation of Salmonella serovars recovered from greyhound feces with their diet. J Vet Diagn Invest 5(3): 378-385.

22. Chengappa MM, Staats J, Oberst RD, Gabbert NH, McVey S (1993) Prevalence of Salmonella in raw meat used in diets of racing greyhounds. J Vet Diagn Invest 5(3): 372-377.

23. Caldow GL, Graham MM (1998) Abortion in foxhounds and ewe flock associated with Salmonella Montevideo infection. Vet Rec 142: 138139.

24. Morley PS, Strohmeyer RA, Tankson JD, Hyatt DR, Dargatz DA, et al (2006) Evaluation of the association between feeding raw meat and Salmonella enterica infections at a Greyhound breeding facility. J Am Vet Med Assoc. 228(10): 1524-1532.

25. Arunee P, Angkititrakul S, Suksawat F, Sparagano O, Kwankate K (2012) Epidemiology and antimicrobial resistance of Salmonella spp. isolated from dogs and cats in Northeastern Thailand. Journal of Animal and Veterinary Advance 11(5): 618-621.

26. Frye JG, Fedorka Cray PJ (2007) Prevalence, distribution and characterization of ceftiofur resistance in Salmonella enterica isolated from animals in the USA from 1999 to 2003. Int J Antimicrob Agents 30(2): 134-142.

27. Lowden $P$, Wallis $C$, Gee N, Hilton A (2015) Investigating the prevalence of Salmonella in dogs within the Midlands region of the United Kingdom. BMC Vet Res 11: 239.

28. Getachew M, Gebru M, Tsehaynesh L, Aseffa A (2014) Prevalence and antimicrobial susceptibility patterns of Salmonella serovars and Shigella species. JMicrobialBiochem Technol S2.

29. Ejeta G, Molla B, Alemayehu D, Muckle A (2004) Salmonella serotypes isolated from minced meat beef, mutton and pork in addis ababa, Ethiopia. Revue Méd Vét 155(11): 547-551.

30. Birhaneselassie M, Williams D (2013) A study of salmonella carriage among asymptomatic food handlers in southern Ethiopia. International Journal of Nutrition and Food Sciences 2(5): 243-245.
31. Weber A, Wachowitz R, Weigl U, Schafer Schmidt R (1995) Occurrence of Salmonella in fecal samples of dogs and cats in northern Bavaria from 1975 to 1994. Berl Munch Tierarztl Wochenschr 108(11): 401404.

32. Tanaka Y, Katsube Y, Imaizumi K (1976) Experimental carrier in dogs produced by oral administration of Salmonella Typhimurium. Nihon Juigaku Zasshi 38(6): 569-578.

33. Molla B, Alemayehu D, Salah W (2003) Sources and distribution of Salmonella serotypes isolated from food animals, slaughterhouse personnel and retail meat products in Ethiopia. Ethiopian Journal of Health Development 17(1): 63-70.

34. Ferede B (2014) Isolation, identification, antimicrobial sensitivity test and public awareness of salmonella on raw goat meat at dire Dawa municipal abattoir, Eastern Ethiopia.

35. Scott MD, Melissa K, Chengappa MM (2013) Enterobacteriaceae: Salmonella. Veterinary Microbiology Text Book ( $3^{\text {rd }}$ edn), Wiley Blackwell, UK.

36. Lindquist N (2008) Molecular characterization of endemic Salmonella Infections in cattle. Faculty of Veterinary Medicine, University of Helsinki, Finland.

37. Quinn PJ, Carter GR, Carter ME, Markey BK (1999) Enterobacteriaceae: Salmonella. Clinical Veterinary Microbiology Text- ( $1^{\text {st }}$ edn), p. 209.

38. The Center for Food Security and Public Health (CoFSPH) (2005) Salmonellosis, Paratyphoid, Non-typhoidal Salmonellosis. College of Veterinary Medicine, Iowa State University, USA, pp. 1-8.

39. Washington State Department of Health (2013) Salmonellosis (nontyphoidal Salmonella). Washington State Guidelines for Notifiable Condition Reporting and Surveillance published in 2002 which were originally based on the Control of Communicable Diseases Manual (CCDM) pp. 1-9.

40. World Health Organization (2003) A Global salmonella surveillance and laboratory support project of the laboratory protocols. Level 1: Training Course Identification of Salmonella ( $4^{\text {th }} \mathrm{edn}$ ).

41. (2008) Salmonella promoting safe pet ownership.

Your next submission with Juniper Publishers
will reach you the below assets
- Quality Editorial service
- Swift Peer Review
- Reprints availability
- E-prints Service
- Manuscript Podcast for convenient understanding
- Global attainment for your research
- Manuscript accessibility in different formats
( Pdf, E-pub, Full Text, Audio)
- Unceasing customer service
Track the below URL for one-step submission
https://juniperpublishers.com/online-submission.php

